\title{
Ischaemic stroke and Clostridium septicum sepsis and meningitis in a patient with occult colon carcinoma - a case report and review of the literature
}

\author{
Kosmas Macha', Antje Giede-Jeppe ${ }^{1}$, Hannes Lücking ${ }^{2}$, Roland Coras ${ }^{3}$, Hagen B. Huttner ${ }^{1}$ and Jürgen Held ${ }^{4 *}$
}

\begin{abstract}
Background: Clostridium septicum is a rare cause of meningitis and brain abscess in children and adults. Gas production by the pathogen can lead to pneumocephalus and the overall mortality rate of Clostridium septicum CNS infection is as high as 74\%. The most common entry site of the pathogen is the gastrointestinal tract.

Case presentation: We describe a 74-year-old man who presented with a left-sided cerebral infarction in the middle cerebral artery territory. In addition the patient showed signs of Systemic Inflammatory Response Syndrome and Disseminated Intravascular Coagulation. Examination of blood cultures and cerebrospinal fluid led to the diagnosis of sepsis and meningitis caused by Clostridium septicum. Despite appropriate antibiotic therapy the condition of the patient deteriorated rapidly and he died on day 2 after admission. Autopsy revealed a previously unknown adenocarcinoma of the colon ascendens as entry site of the pathogen.

Conclusion: Clostridium septicum should be considered as potential pathogen in patients with sepsis and meningitis. Gram stain morphology in conjunction with severe sepsis can rapidly point into the direction of this pathogen. CNS infections manifest either as meningoencephalitis/cerebritis or as brain abscess. Entry site of the pathogen is almost uniquely the gastrointestinal tract. In adults more than 50\% suffer from colorectal carcinoma, therefore survivors of Clostridium septicum infections should be examined for underlying occult colorectal malignancy.
\end{abstract}

Keywords: CNS infection, Pneumocephalus, Cerebritis, Meningoencephalitis, Sepsis, DIC, Ischemic stroke, Bacteremia

\section{Background}

The seven main pathogens causing community-aquired bacterial meningitis (Streptococcus pneumoniae (72\%), Neisseria meningitidis (11\%), Listeria monocytogenes (5\%), Haemophilus influenzae (3\%), Streptococcus pyogenes (2\%), Streptococcus agalactiae (1\%), Staphylococcus aureus (1\%)) account for $96 \%$ of infections [1]. Clostridium septicum is a rare cause of central nervous system (CNS) infection. It manifests either as meningoencephalitis/cerebritis or as brain abscess and is associated with high morbidity and mortality $[2,3]$.

\footnotetext{
* Correspondence: juergen.held@uk-erlangen.de

${ }^{4}$ Mikrobiologisches Institut, Universitätsklinikum Erlangen,

Friedrich-Alexander-Universität Erlangen-Nürnberg (FAU), Wasserturmstraße

3-5, 91054 Erlangen, Germany

Full list of author information is available at the end of the article
}

Here we describe a case of sepsis and meningitis caused by Clostridium septicum complicated with ischemic stroke and review the literature with a focus on pathogen, portal of entry, therapy and outcome.

\section{Case presentation}

A 74-year-old man was admitted to our emergency department in a somnolent state of consciousness with left gaze preference, aphasia, and right-sided hemiparesis (National Institutes of Health Stroke Scale, NIHSS-score: 17). The symptoms were first realized after awakening. Cranial computed tomography and angiography revealed a left-sided infarction in the middle cerebral artery (MCA) territory caused by a peripheral MCA occlusion (Fig. 1). In addition the patient showed signs of Systemic Inflammatory Response Syndrome (SIRS) and Disseminated 

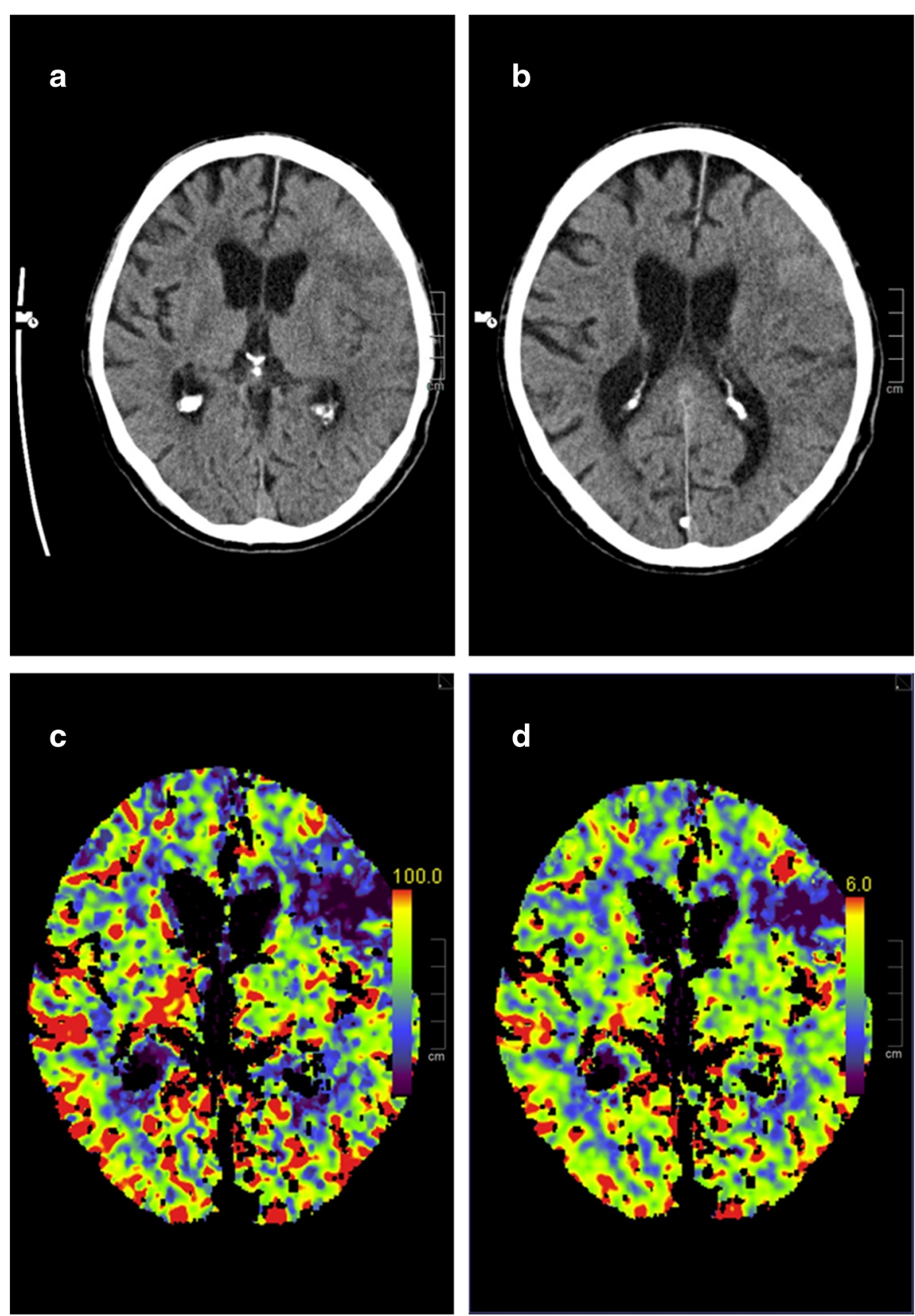

Fig. 1 Non-contrast $C T$ at admission showing left-sided MCA-infarction $(\mathbf{a}, \mathbf{b})$. CT-perfusion showing reduced perfusion of the left anterior MCAterritory in Cerebral Blood Flow (CBF)- (c) and Cerebral Blood Volume (CBV)-measurements (d)

Intravascular Coagulation (DIC) (body temperature $41.1{ }^{\circ} \mathrm{C}$, heart rate $140 / \mathrm{min}$, respiratory rate $17 / \mathrm{min}$, leucocytes $4.17 \times 10^{\wedge} 3 /$ ul, C-reactive protein $(\mathrm{CRP})$ $54.3 \mathrm{mg} / \mathrm{l}$, platelet count $\left.111 \times 10^{\wedge} 3 / \mathrm{ul}\right)$. Intravenous fluid therapy was started immediately. After acquisition of blood cultures and cerebrospinal fluid (CSF), an empiric antibiotic therapy with ceftriaxone, ampicillin and aciclovir was initiated. Soon after, the patient required cardiopulmonary resuscitation in the setting of septic shock.
After intubation and cardiopulmonary stabilization the patient was admitted to the neuro-intensive care unit. CSF examination showed 390 leucocytes $/ \mathrm{ml}$, elevated lactate (5.52 $\mathrm{mmol} / \mathrm{l})$ and protein levels $(2783 \mathrm{mg} / \mathrm{l})$ as well as normal glucose levels (66\% of serum levels). Immediate Gram staining of CSF revealed partially elongated, Grampositive rods without spore formation. Because of their size and appearance Listeria spp. could be ruled out and Bacillus spp. or Clostridium spp. were suspected (Fig. 2a). 



Fig. 2 Gram stain morphology of Clostridium septicum from CSF (a) and blood culture (b) in 1000x magnification. Interestingly, spore formation (arrow) was only observed in Gram stains from blood cultures

Therefore the antibiotic therapy was escalated with vancomycin. On the following day anaerobic blood cultures grew also Gram-positive rods with some of them showing endospore formation (Fig. 2b). Aerobic blood cultures remained sterile. Accordingly, sepsis and meningitis by Clostridium spp. were assumed. Culture results confirmed this tentative diagnosis and the bacteria were identified by mass spectroscopy as Clostridium septicum. Antibiotic susceptibility testing showed that the strain was sensitive to penicillin G, imipenem, clindamycin, vancomycin and metronidazole with minimal inhibitory concentration of $0.023 \mathrm{mg} / \mathrm{l}, 0.006 \mathrm{mg} / \mathrm{l}, 0.032 \mathrm{mg} / \mathrm{l}, 0.75 \mathrm{mg} / \mathrm{l}$ and $0.25 \mathrm{mg} /$ 1 , respectively. Respiratory specimens and urine were unremarkable. Transthoracic echocardiography did not show endocarditis and there was no sign of an infection focus in ear, nose, throat or the sinuses. The further course was characterized by a persistent severe septic disease pattern with high demand of catecholamines, strong increase of inflammation parameters (leucocytes max. $42.86 \times 10^{3} / \mathrm{ul}$, procalcitonin (PCT) max. $177.32 \mathrm{ng} / \mathrm{ml}$, CRP max. $398.8 \mathrm{mg} / \mathrm{l})$. The antibiotic therapy was switched to high dose penicillin $G$ and clindamycin. The inflammatory parameters started to decrease approximately $48 \mathrm{~h}$ after initiation of empiric antibiotic therapy. However, because the patient showed a persistent loss of brain stem reflexes after initial cardiopulmonary resuscitation, it was decided to change the therapy to a palliative regimen. The patient died two days post admission. Due to the fact that no obvious risk factors for Clostridium septicum bacteremia were present (e.g. infected wounds, myonecrosis, diabetes mellitus, severe atherosclerotic cardiovascular disease, neutropenia, liver cirrhosis), a previously unknown gastrointestinal focus of infection was most likely [4]. Accordingly, autopsy revealed an adenocarcinoma of the colon ascendens with $2.8 \mathrm{~cm}$ in diameter as entry site of the pathogen.

\section{Discussion}

The leading neurological symptoms of our patient were those of a left sided stroke in the MCA-territory which was confirmed by cranial computed tomography and angiography.

At the same time the patient suffered from bacterial sepsis and meningitis. The question in dispute is what came first? One order of events is that Clostridium septicum crossed the gastrointestinal barrier and entered the blood stream with the colon carcinoma as entry site. From the blood it spread to the CNS causing meningitis. In parallel, the sepsis lead to a DIC which on its part resulted in hypercoagulation and cerebral infarction. The stroke would have been a consequence of invasive clostridial infection.

A second possibility is that the stroke was the initial event leading to a compromised immune response and/or by stress-mediated paralytic ileus to an impaired intestinal barrier [5]. This enabled Clostridium septicum to enter the blood stream and supported by the stroke-induced damage of the blood-brain barrier (locus minoris resistentiae) to cause CNS infection. The invasive clostridial infection would have been a consequence of the stroke.

Two facts argue against the second hypothesis. First, the stroke was a wake-up stroke and sepsis and DIC were already apparent at admission. Therefore, the stroke induced impairment of the intestinal barrier must have developed within a couple of hours which is rather unlikely. Second, no bacteria were detected microscopically in the stroke area during brain autopsy and the published cases of Clostridium septicum CNS infections showed that the pathogen does not need an impaired blood-brain barrier to cause meningitis.

In our opinion the first hypothesis is more likely although we cannot rule out the second sequence of events with certainty.

The first hint on the nature of the pathogen was its CSF Gram stain morphology. All the major pathogens can be distinguished by their different appearance in the Gram staining. Only Listeria monocytogenes is Gram-positive and rod-shaped. However, size and shape of the Gram-positive rods in our patient pointed towards Bacillus or Clostridium spp. as pathogens. To cover possible Bacillus-infection the 
addition of vancomycin to the empiric antibiotic regimen with ampicillin and ceftriaxon was reasonable.

Clostridia are obligately anaerobic, gram-positive rods. Because of their ability to produce environmentally resistant endospores they are widespread in nature and are commonly found in soil and the intestinal tracts of humans and animals. Clostridia produce more kinds of protein toxins than any other bacterial genus causing diseases like tetanus, botulism, enterocolitis and anaerobic myonecrosis (gas gangrene). One important species is Clostridium septicum. Due to production of its 4 major exotoxins $(\alpha-, \beta-, \gamma$ - and $\delta$-toxin) it is able to cause myonecrosis. In line with Clostridium perfringens and Clostridium tertium it is the third most common Clostridium spp. causing sepsis [4]. Patients with bacteremia by this organism are usually severely ill and mortality rates rise up to 70\% [3]. More than 50\% suffer from some kind of gastrointestinal pathology, such as diverticular disease, or an underlying malignancy, such as colorectal carcinoma. Further risk factors for clostridial bacteremia include neutropenia with or without enterocolitis, diabetes mellitus or gas gangrene [4]. Whether Clostridium septicum colonizes the human gastrointestinal tract is still under debate. However, a breach in the mucosal barrier for example by enterocolitis or colorectal cancers is required for invasive infection [3].

A rare complication of Clostridium septicum bacteremia is a hematogenous spread to the CNS. CNS infections manifest either as meningoencephalitis/cerebritis or as brain abscess [2]. Because of the ability of Clostridium septicum to produce gas a pneumocephalus may result that can be localized or diffuse [6-8]. Brain autopsy in our patient confirmed a haemorrhagic infarction in the left MCA territory. There were signs of diffuse inflammation at supra- and infratentorial areas in terms of a meningoencephalitis. An infectious agent and/or gas production could not be verified at microscopic level.

Table 1 summarizes the 19 published cases of Clostridium septicum CNS infections. $79 \%$ of the patients were

Table 1 Summary of published Clostridium septicum CNS infections

\begin{tabular}{|c|c|c|c|c|c|c|}
\hline First Author & Age [years] & Sex & CNS manifestation & Underlying disease & Outcome & Day of death after admission \\
\hline Bhogal P [3] & $80-89$ & female & $\begin{array}{l}\text { Meningoencephalitis } \\
\text { with pneumocephalus }\end{array}$ & Gastroenteritis & Died & 1 \\
\hline Broughton RA [10] & 2 & female & Meningoencephalitis & HUS & Died & 1 \\
\hline Cheng YT [2] & 40 & female & Brain abscess & $\begin{array}{l}\text { Multiple wounds, breast } \\
\text { cancer }\end{array}$ & Survived & - \\
\hline Chiang V [11] & 2 & male & Brain abscess & HUS & Survived & - \\
\hline Dirks C [12] & 72 & female & $\begin{array}{l}\text { Meningoencephalitis } \\
\text { with pneumocephalus }\end{array}$ & Myonecrosis & Died & 1 \\
\hline Gorse GJ [13] & 76 & male & $\begin{array}{l}\text { Meningoencephalitis } \\
\text { with pneumocephalus }\end{array}$ & Colorectal carcinoma & Died & 1 \\
\hline Gorse GJ [13] & 33 & male & $\begin{array}{l}\text { Meningoencephalitis } \\
\text { with pneumocephalus }\end{array}$ & $\begin{array}{l}\text { Aplastic anemia with } \\
\text { splenectomy }\end{array}$ & Died & 2 \\
\hline Habscheid W [14] & 55 & male & $\begin{array}{l}\text { Meningoencephalitis } \\
\text { with pneumocephalus }\end{array}$ & Neutropenic enterocolitis & Died & 2 \\
\hline Macha K* & 74 & male & Meningoencephalitis & Colorectal carcinoma & Died & 3 \\
\hline Katyal A [6] & 66 & male & $\begin{array}{l}\text { Meningoencephalitis } \\
\text { with pneumocephalus }\end{array}$ & Unknown & Died & 1 \\
\hline Kolbeinsson MW [15] & 71 & male & Brain abscess & MDS & Survived & - \\
\hline Mrangou AG [16] & 85 & male & Brain abscess & Colorectal carcinoma & Died & 16 \\
\hline Martin SE [7] & 2 & male & $\begin{array}{l}\text { Meningoencephalitis } \\
\text { with pneumocephalus }\end{array}$ & HUS & Died & 1 \\
\hline Ragland RL [17] & 67 & male & $\begin{array}{l}\text { Meningoencephalitis } \\
\text { with pneumocephalus }\end{array}$ & Colorectal carcinoma & Died & 1 \\
\hline Randall JM [8] & 4 & male & $\begin{array}{l}\text { Meningoencephalitis } \\
\text { with pneumocephalus }\end{array}$ & HUS & Died & 3 \\
\hline Riccio JA [18] & 1 & male & $\begin{array}{l}\text { Meningoencephalitis } \\
\text { with pneumocephalus }\end{array}$ & HUS & Died & 1 \\
\hline Roeltgen D [19] & 73 & female & $\begin{array}{l}\text { Meningoencephalitis } \\
\text { with pneumocephalus }\end{array}$ & Colorectal carcinoma & Died & 1 \\
\hline Sadarangani SP [20] & 1 month & male & Brain abscess & Necrotizing enterocolitis & Survived & - \\
\hline Williams EJ [21] & 2 & male & Brain abscess & HUS & Survived & - \\
\hline
\end{tabular}

*This patient is described in the present case report 
either younger than 3 or older than 65 years of age. Nearly all affected children had hemolytic uremic syndrome probably after gastrointestinal infection with Enterohemorrhagic Escherichia coli and more than half (63\%) of the patients older than 65 years suffered from colorectal carcinoma.

According to our literature review the overall mortality in patients with Clostridium septicum CNS infection is $74 \%$ (5 survivors, 14 deceased) and most patients died within the first $48 \mathrm{~h}(79 \%)$. Interestingly, the mortality of brain abscess with the possibility of a surgical intervention is significantly lower than that of meningoencephalitis with antibiotic therapy alone (17\% versus $100 \%, p=0.001)$.

Therefore, therapeutic management of Clostridium septicum CNS infection consists of antibiotic therapy and, if possible, surgery/aspiration of the brain abscess. Antibiotics with low MICs are penicillin G, cefazolin, clindamycin and rifampin. A combination therapy of penicillin plus clindamycin or rifampin might be beneficial [9]. Prognosis of meningoencephalitis with antibiotic therapy alone is poor and it seems essential for survival that a localized process (e.g. an abscess) exists that is accessible to surgical interventions.

\section{Conclusions}

Clostridium septicum should be considered as potential pathogen in patients with sepsis and meningitis. Gram stain morphology in conjunction with severe sepsis can rapidly point into the direction of this pathogen. Detailed microbiological analysis is required for identification and appropriate antibiotic therapy. If a localized process in the CNS is present a surgical intervention seems to be essential for survival. Adult patients with Clostridium septicum infection should be examined for underlying occult gastrointestinal disease or cancer.

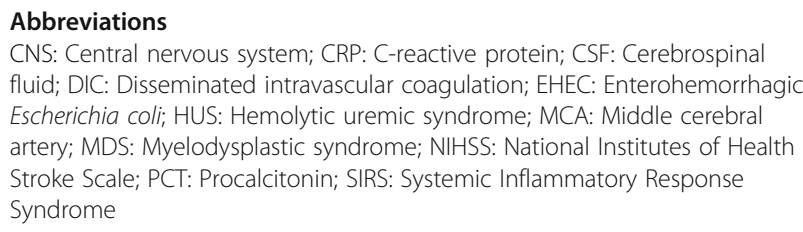

\section{Acknowledgments}

None.

Funding

None.

Availability of data and materials

The dataset supporting the conclusion of this article is included within the article.

\section{Authors' contributions}

KM and AJG acquired clinical data and drafted the manuscript. HL performed the neuroradiological examination and acquired the neuroradiological data. RC performed the neuropathological examination and acquired the neuropathological data. JH performed the microbiologic examination, acquired microbiological data and drafted the manuscript. HBH contributed to the development of the manuscript. All authors interpreted the data and revised the manuscript critical for important intellectual content. All authors have read and approved the final version of the manuscript. KM and AGJ contributed equally as co-first authors.

\section{Competing interest}

The authors declare that they have no competing interest.

\section{Consent for publication}

Written informed consent was obtained from the patient's wife. A copy of the written consent is available for review by the Editor-in-Chief of this journal.

Ethics approval and consent to participate

The authors declare that ethics approval was not required for this case report.

\section{Author details}

'Department of Neurology, Universitätsklinikum Erlangen, Friedrich-Alexander-Universität Erlangen-Nürnberg (FAU), Schwabachanlage 6, 91054 Erlangen, Germany. ${ }^{2}$ Department of Neuroradiology, Universitätsklinikum Erlangen, Friedrich-Alexander-Universität Erlangen-Nürnberg (FAU), Schwabachanlage 6, 91054 Erlangen, Germany. ${ }^{3}$ Department of Neuropathology, Universitätsklinikum Erlangen,

Friedrich-Alexander-Universität Erlangen-Nürnberg (FAU), Schwabachanlage 6, 91054 Erlangen, Germany. ${ }^{4}$ Mikrobiologisches Institut, Universitätsklinikum Erlangen, Friedrich-Alexander-Universität Erlangen-Nürnberg (FAU),

Wasserturmstraße 3-5, 91054 Erlangen, Germany.

Received: 17 May 2016 Accepted: 11 November 2016

Published online: 24 November 2016

\section{References}

1. Bijlsma MW, Brouwer MC, Kasanmoentalib ES, Kloek AT, Lucas MJ, Tanck MW, van der Ende A, van de Beek D. Community-acquired bacterial meningitis in adults in the Netherlands, 2006-14: a prospective cohort study. Lancet Infect Dis. 2016;16:339-47.

2. Cheng YT, Huang CT, Leu HS, Chen JS, Kiu MC. Central nervous system infection due to Clostridium septicum: a case report and review of the literature. Infection. 1997;25:171-4.

3. Bhogal P, Bhatnagar G, Manieson J, Booth T, Prendergast C. An unusual case of pneumocephalus. BMJ case reports. 2011; doi: 10.1136/bcr.06.2010.3106.

4. Stevens DL, Bryant AE, Berger A, von Eichel-Streiber C. Clostridium. In: Versalovic J CK, Jorgensen JH, Funke G, Landry ML, Warnock DW. Manual of Clinical Microbiology. Washington: ASM press; 2011. p.834-57.

5. Singh V, Roth S, Llovera G, Sadler R, Garzetti D, Stecher B, Dichgans M, Liesz A. Microbiota Dysbiosis Controls the Neuroinflammatory Response after Stroke. J Neurosci. 2016:36:7428-40.

6. Katyal A, Dmello D. Clostridium septicum Pneumocephalus. Neurocrit Care. 2016;24:264-7.

7. Martin SE, Allen SD, Faught P, Hawley DA, Bonnin JM, Hattab EM. A 2-yearold boy with hemolytic uremic syndrome and pneumocephalus. Brain Pathol. 2012;22:121-4

8. Randall JM, Hall K, Coulthard MG. Diffuse pneumocephalus due to Clostridium septicum cerebritis in haemolytic uraemic syndrome: CT demonstration. Neuroradiology. 1993;35:218-20.

9. Gabay EL, Rolfe RD, Finegold SM. Susceptibility of Clostridium septicum to 23 antimicrobial agents. Antimicrob Agents Chemother. 1981;20:852-3.

10. Broughton RA, Lee EY. Clostridium septicum sepsis and meningitis as a complication of the hemolytic-uremic syndrome. Clin Pediatr (Phila). 1993; 32:750-2.

11. Chiang V, Adelson PD, Poussaint TY, Hand M, Churchwell KB. Brain abscesses caused by Clostridium septicum as a complication of hemolyticuremic syndrome. Pediatr Infect Dis J. 1995;14:72-4.

12. Dirks C, Horn H, Christensen L, Pedersen C. CNS infection with clostridium septicum. Scand J Infect Dis. 2000;32:320-2.

13. Gorse GJ, Slater LM, Sobol E, Kim RC, Wishnow RM, Cesario TC. CNS infection and bacteremia due to clostridium septicum. Arch Neurol. 1984;41:882-4.

14. Habscheid W, Bernhardt C, Sold M, Köhler B, Marx A, Kunz E, MüllerHermelink HK. Atraumatic Clostridium septicum infection in granulocytopenia. Dtsch Med Wochenschr. 1991;116:1862-6. 
15. Kolbeinsson ME, Holder Jr WD, Aziz S. Recognition, management, and prevention of Clostridium septicum abscess in immunosuppressed patients. Arch Surg. 1991;126:642-5.

16. Marangou AG, Joske RA, Kaard AO, Thomas W. Cerebral abscess due to Clostridium septicum. J R Soc Med. 1992;85:641.

17. Ragland RL, Knorr JR, Lee GM, DeGirolami U, Gelber ND. Clostridium septicum meningoencephalitis: an unusual presentation of occult rectal carcinoma. Am J Neuroradiol. 1992;13:1487-8.

18. Riccio JA, Oberkircher OR. Clostridium septicum sepsis and cerebritis: a rare complication of the hemolytic-uremic syndrome. Pediatr Infect Dis J. 1988;7:342-5

19. Roeltgen D, Shugar G, Towfighi J. Cerebritis due to Clostridium septicum. Neurology. 1980;30:1314-6.

20. Sadarangani SP, Batdorf R, Buchhalter LC, Mrelashvili A, Banerjee R, Henry NK, Huskins WC, Boyce TG. Clostridium septicum brain abscesses in a premature neonate. Pediatr Infect Dis J. 2014;33:538-40.

21. Williams EJ, Mitchell P, Mitra D, Clark JE. A microbiological hazard of rural living: Clostridium septicum brain abscess in a child with E coli 0157 associated haemolytic uraemic syndrome. BMJ Case Rep. 2012; doi: 10.1136/ bcr-2012-006424.

Submit your next manuscript to BioMed Central and we will help you at every step:

- We accept pre-submission inquiries

- Our selector tool helps you to find the most relevant journal

- We provide round the clock customer support

- Convenient online submission

- Thorough peer review

- Inclusion in PubMed and all major indexing services

- Maximum visibility for your research

Submit your manuscript at www.biomedcentral.com/submit
) Biomed Central 